\title{
Improved Perturbation Solutions for Laminar Natural Convection on a Vertical Cylinder
}

\author{
A. Aziz, Riyadh, Saudi Arabia and T. Y. Na, Dearborn, Michigan, USA
}

\begin{abstract}
The method of extended perturbation series is applied to solve for laminar natural convection from an isothermal, thin vertical cylinder. The series in terms of the transverse curvature parameter $\xi$ extended to five terms and is subsequently improved by applying the Shanks transformation twice. The validity of the solution is extended up to $\xi=10$ and possibly even beyond. Up to $\xi=10$, the results for wall shear as well as the local and average Nusselt numbers agree very closely with those of local nonsimilarity and finite difference solutions. The ease of computation coupled with high accuracy makes the present approach far more attractive than the currently popular local nonsimilarity and finite difference methods. Its success with the present problem should motivate applications to a host of nonsimilar boundary layer flows.
\end{abstract}

Verbesserte Störungslösungen für laminare freie Konvektion am senkrechten Zylinder

Zusammenfassung. Die Methode der erweiterten Störungsserien wird auf die laminare freie Konvektion am isothermen senkrechten dünnen Zylinder angewendet. Die Serien in Ausdrücken des Krümmungsparameters $\xi$ werden auf 5 Terme ausgedehnt und weiter durch doppelte Auswertung der Shank-Transformation verbessert. Die Lösung gilt mindestens bis $\xi=10$, vielleicht sogar weiter. Bis $\xi=10$ stimmen die Lösungen für die Wandschubspannung und die örtliche und mittlere Nußelt-Zahl gut überein mit jenen, die auf der örtlichen Nicht-Ähnlichkeit und finiten Differenzen beruhen. Die leichte Berechenbarkeit und die hohe Genauigkeit machen diesen Lösungsweg attraktiver als die heute populären Verfahren der örtlichen Nicht-Ähnlichkeit und der finiten Differenzen. Der hier aufgezeigte Erfolg sollte zur Anwendung auf nicht-ähnliche Grenzschichtströmungen motivieren.

\section{Nomenclature}

e operator defined by Eq. (31)

$F$ dimensionless stream function

$F_{n} \quad n$th order approximation for dimensionless stream function

$g$ acceleration of gravity

$h$ local heat transfer coefficient

$\bar{h}$ average heat transfer coefficient

$k$ thermal conductivity

$\mathrm{Nu}_{x}$ local Nusselt number, $h x / k$

$\overline{\mathrm{Nu}}_{x} \quad$ average Nusselt number, $\bar{h} x / k$

Pr Prandtl number, $v / \alpha$

$r$ radial coordinate

$r_{0} \quad$ radius of cylinder

\author{
$T \quad$ temperature \\ $T_{\mathrm{w}} \quad$ wall temperature of cylinder \\ $T_{\infty} \quad$ ambient temperature \\ $u, v \quad$ velocity components \\ $x$ axial coordinate \\ Greek symbols \\ $\alpha \quad$ thermal diffusivity \\ $\beta \quad$ coefficient of thermal expansion \\ $\eta \quad$ similarity variable, Eq. (7) \\ $\theta \quad$ dimensionless temperature, $\left(T-T_{\infty}\right) /\left(T_{\mathrm{w}}-T_{\infty}\right)$ \\ $\theta_{n} \quad n$th order approximation for dimensionless temperature \\ $v \quad$ kinematic viscosity \\ $\xi \quad$ transverse curvature parameter, Eq. (8) \\ $\psi \quad$ stream function
}

Subscripts

fp flat plate

cyl cylinder

\section{Introduction}

Current interest in laminar boundary layer flows centers around nonsimilar flows and their solution techniques. The nonsimilarities arise due to a number of factors such as variable freestream velocity, mass transfer, transverse curvature, complicated thermal boundary conditions etc. Over the years a number of techniques have been developed and applied to such problems. To discuss the relative merits of different techniques, we will concentrate on the problem of natural convection from the outer surface of an isothermal vertical, thin cylinder. In this case the nonsimilarity is due to the transverse curvature effect which becomes quite significant when the radius of the cylinder and the boundary layer thickness are of comparable magnitude. Among the procedures used to solve this problem are the heat balance integral [1, 2], local nonsimilarity [3], two-point finite difference [4] and the perturbation expansion [5-7].

For the uniform surface temperature, the heat balance integral results [1] for the average Nusselt number have been found to be substantially in error in the light of local 
nonsimilarity solution [3]. However, the local nonsimilarity method, which is currently very popular, in itself involves considerable difficulties. For example, the third level truncation requires the solution of fifteen nonlinear, simultaneous ordinary differential equations with six missing initial conditions. The standard shooting procedure runs into problem of poor or no convergence and consequently excessive computational cost. The situation is particularly serious at higher degrees of nonsimilarity [3]. To ensure more rapid convergence, a new scheme has been proposed recently [8] in which the governing differential equations are replaced by integral equations. However, the execution of the new scheme necessitated further refinements such as the division of boundary layer thickness into four zones, use of variable step size and incorporation of experience based under relaxation factor. With the finite difference proposed in [4], one is led to highly implicit and nonlinear equations, the solution of which often entails convergence difficulties. It would seem that the perturbation approach is much simpler because, except for the zero-order problem, the subsequent order problems are all linear and therefore very easily solved. On the other hand, the disadvantage is that the expansion, if terminated at the third term as in [5-7], is valid for only small values of curvature parameter $\xi$, that is $\xi<1$. If the restriction of small $\xi$ can somehow be removed it is obvious that the method can become very attractive. Indeed, the purpose of the present contribution is to demonstrate how this restriction can be overcome and the series improved so as to be applicable at high values of $\xi$.

The tool to be employed is the method of extended perturbation series and its subsequent improvement. This method has proved extremely effective in fluid mechanics for many years [9] but only very recently in nonlinear heat conduction [10]. However, its applicability to nonsimilar boundary layer flows has hitherto remained unexplored. The specific approach to be used here is to extend the series (in terms of $\xi$ ) to five terms and then apply the Shanks transformation twice. With this artifice, the validity of the expansion is extended to $\xi=10$ and possibly beyond. The expansion thus covers the entire range of $\xi$ for which the local nonsimilarity and finite difference results have been reported. It will be seen that the present results for both the wall shear as well as local and average Nusselt numbers agree very closely with those of local nonsimilarity and finite difference.

In testing the method we chose a natural convection problem rather than a forced convection problem because it was felt that with coupled velocity and temperature fields it provided a more challenging test for the effectiveness of the method.

\section{Governing Equations}

Let us consider a thin vertical cylinder of radius $r_{0}$ maintained at a uniform temperature $T_{\mathrm{w}}$ and convecting naturally to an environment at temperature $T_{\infty}$. The radial coordinate $r$ is measured from the axis of the cylinder while the axial coordinate $x$ is measured vertically upward such that $x=0$ corresponds to the leading edge where the boundary layer thickness is zero.

Based on the usual Boussinesq model, the governing equations can be written as

$$
\begin{aligned}
& \frac{\partial}{\partial x}(r u)+\frac{\partial}{\partial r}(r v)=0 \\
& u \frac{\partial u}{\partial x}+v \frac{\partial u}{\partial r}=g \beta\left(T-T_{\infty}\right)+\frac{v}{r} \frac{\partial}{\partial r}\left(r \frac{\partial u}{\partial r}\right) \\
& u \frac{\partial T}{\partial x}+v \frac{\partial T}{\partial r}=\frac{\alpha}{r} \frac{\partial}{\partial r}\left(r \frac{\partial T}{\partial r}\right) \\
& r=r_{0}, \quad u=v=0, \quad T=T_{\mathrm{w}} \\
& r=\infty, \quad u=0, \quad T=T_{\infty}
\end{aligned}
$$

By defining the stream function $\psi$, pseudo-similarity variable $\eta$, transverse curvature parameter $\xi$ and dimensionless temperature $\theta$ as

$$
\begin{aligned}
& \psi=4 v r_{0} x^{3 / 4}\left[\frac{g \beta\left(T_{\mathrm{w}}-T_{\infty}\right)}{4 v^{2}}\right]^{1 / 4} F(\xi, \eta) \\
& \eta=\left[\frac{g \beta\left(T_{\mathrm{w}}-T_{\infty}\right)}{4 v^{2}}\right]^{1 / 4} \frac{\left(r^{2}-r_{0}^{2}\right)}{2 r_{0} x^{1 / 4}} \\
& \xi=\frac{2\left(x / r_{0}\right)^{1 / 4}}{\left[g \beta\left(T_{\mathrm{w}}-T_{\infty}\right) r_{0}^{3 / 4} v^{2}\right]^{1 / 4}} \\
& \theta(\xi, \eta)=\frac{T-T_{\infty}}{T_{\mathrm{w}}-T_{\infty}}
\end{aligned}
$$

and introducing them in Eqs. $(1-5)$ yields

$$
\begin{aligned}
& (1+\xi \eta) F^{\prime \prime \prime}+\xi F^{\prime \prime}+3 F F^{\prime \prime}-2\left(F^{\prime}\right)^{2}+\theta \\
& \quad=\xi\left[F^{\prime} \frac{\partial F^{\prime}}{\partial \xi}-F^{\prime \prime} \frac{\partial F}{\partial \xi}\right] \\
& (1+\xi \eta) \theta^{\prime \prime}+\xi \theta^{\prime}+3 \operatorname{Pr} F \theta^{\prime}=\operatorname{Pr} \xi\left[F^{\prime} \frac{\partial \theta}{\partial \xi}-\theta^{\prime} \frac{\partial F}{\partial \xi}\right] \\
& \eta=0, \quad F=F^{\prime}=0, \quad \theta=1 \\
& \eta=\infty, \quad F^{\prime}=0, \quad \theta=0
\end{aligned}
$$

where primes denote differentiation with respect to $\eta$.

\section{Perturbation Expansion}

To solve Eqs. $(10-13)$ we assume a regular perturbation expansion for $T$ and $\theta$ in powers of $\xi$ as

$$
\begin{aligned}
& F=\sum_{n=0}^{\infty} \xi^{n} F_{n} \\
& \theta=\sum_{n=0}^{\infty} \xi^{n} \theta_{n}
\end{aligned}
$$


Substituting $(14,15)$ into Eqs. $(10,11)$, equating coefficients of like powers of $\xi$ and truncating the expansion at the fifth term, we have

$$
\begin{aligned}
\xi^{0}: \quad F_{0}^{\prime \prime} & +3 F_{0} F_{0}^{\prime \prime}-2\left(F_{0}^{\prime}\right)^{2}+\theta_{0}=0 \\
\theta_{0}^{\prime \prime} & +3 \operatorname{Pr} F_{0} \theta_{0}^{\prime}=0 \\
\xi^{\prime 1}: \quad F_{1}^{\prime \prime} & +3 F_{0} F_{1}^{\prime \prime}-5 F_{0}^{\prime} F_{1}^{\prime}+4 F_{0}^{\prime \prime} F_{1}+\theta_{1} \\
& +\eta F_{0}^{\prime \prime}+F_{0}^{\prime \prime}=0 \\
\theta_{1}^{\prime \prime} & +3 \operatorname{Pr} F_{0} \theta_{1}^{\prime}-\operatorname{Pr} F_{0}^{\prime} \theta_{1}+4 \operatorname{Pr} F_{1} \theta_{0}^{\prime} \\
& +\eta \theta_{0}^{\prime \prime}+\theta_{0}^{\prime}=0
\end{aligned}
$$

$\xi^{2}: \quad F_{2}^{\prime \prime \prime}+3 F_{0} F_{2}^{\prime \prime}-6 F_{0}^{\prime} F_{2}^{\prime}+5 F_{0}^{\prime \prime} F_{2}+\theta_{2}+\eta F_{1}^{\prime \prime \prime}$

$$
+F_{1}^{\prime \prime}+4 F_{1} F_{1}^{\prime \prime}-3\left(F_{1}^{\prime}\right)^{2}=0
$$$$
\theta_{2}^{\prime \prime}+3 \operatorname{Pr} F_{0} \theta_{2}^{\prime}-2 \operatorname{Pr} F_{0}^{\prime} \theta_{2}+5 \operatorname{Pr} \theta_{0}^{\prime} F_{2}+\eta \theta_{1}^{\prime \prime}
$$$$
+\theta_{1}^{\prime}+4 \operatorname{Pr} F_{1} \theta_{1}^{\prime}-\operatorname{Pr} \theta_{1} F_{1}^{\prime}=0
$$

$\xi^{3}: \quad F_{3}^{\prime \prime \prime}+3 F_{0} F_{3}^{\prime \prime}-7 F_{0}^{\prime} F_{3}^{\prime}+6 F_{0}^{\prime \prime} F_{3}+\theta_{3}+\eta F_{2}^{\prime \prime \prime}$

$+F_{2}^{\prime \prime}+4 F_{1} F_{2}^{\prime \prime}+5 F_{2} F_{1}^{\prime \prime}-7 F_{1}^{\prime} F_{2}^{\prime}=0$

$\theta_{3}^{\prime \prime}+3 \operatorname{Pr} F_{0} \theta_{3}^{\prime}-3 \operatorname{Pr} F_{0}^{\prime} \theta_{3}+6 \operatorname{Pr} F_{3} \theta_{0}^{\prime}+\eta \theta_{2}^{\prime \prime}$

$+\theta_{2}^{\prime}+\operatorname{Pr}\left(F_{1} \theta_{2}^{\prime}+F_{2} \theta_{1}^{\prime}\right)-\operatorname{Pr}\left(\theta_{1} F_{2}^{\prime}+2 \theta_{2} F_{1}^{\prime}\right.$

$\left.-3 \theta_{2}^{\prime} F_{1}-4 \theta_{1}^{\prime} F_{2}\right)=0$

$$
\begin{aligned}
\xi^{4}: \quad F_{4}^{\prime \prime \prime} & +3 F_{0} F_{4}^{\prime \prime}-8 F_{0}^{\prime} F_{4}^{\prime}+7 F_{0}^{\prime \prime} F_{4}+\theta_{4}+\eta F_{3}^{\prime \prime \prime} \\
& +F_{3}^{\prime \prime}+4 F_{1} F_{3}^{\prime \prime}+5 F_{2} F_{2}^{\prime \prime}+6 F_{3} F_{1}^{\prime \prime}-8 F_{1}^{\prime} F_{3}^{\prime} \\
& -4\left(F_{2}^{\prime}\right)^{2}=0 \\
\theta_{4}^{\prime \prime} & +3 \operatorname{Pr} F_{0} \theta_{4}^{\prime}-4 \operatorname{Pr} F_{0}^{\prime} \theta_{4}+7 \operatorname{Pr} \theta_{0}^{\prime} F_{4}+\eta \theta_{3}^{\prime \prime} \\
& +\theta_{3}^{\prime}+4 \operatorname{Pr} F_{1} \theta_{3}^{\prime}+5 \operatorname{Pr} F_{2} \theta_{2}^{\prime}+6 \operatorname{Pr} F_{3} \theta_{1}^{\prime} \\
& -\operatorname{Pr}\left(F_{3}^{\prime} \theta_{1}+2 F_{2}^{\prime} \theta_{2}+3 F_{1}^{\prime} \theta_{3}\right)=0
\end{aligned}
$$

The boundary conditions $(4,5)$ transform to

$$
\begin{array}{ll}
\eta=0, & F_{n}=0, \quad F_{n}^{\prime}=0, \quad n=0,1,2,3,4 \\
\eta=0, & \theta_{0}=1, \quad \theta_{n}=0, \quad n=1,2,3,4 \\
\eta=\infty, & F_{n}^{\prime}=0, \quad n=0,1,2,3,4 \\
\eta=\infty, & \theta_{n}=0, \quad n=0,1,2,3,4
\end{array}
$$

The zero-order approximation given by Eqs. $(16,17)$ corresponds to a flat plate and its solution is well known. The subsequent order problems (Eqs. 20-25) involve linear simultaneous equations and were solved noniteratively by the method of superposition [11].

\section{Results and Discussion}

The results of numerical computation of Eqs. (16-25) are summarized in Table 1 for $\operatorname{Pr}=0.72,1,10$ and 100. Only values of $F_{n}^{\prime \prime}(0)$ and $\theta_{n}^{\prime}(0)$ are given which are relevant to the calculation of wall shear and heat transfer rate respectively.
Table 1. Values of $F_{n}^{\prime \prime}(0)$ and $\theta_{n}^{\prime}(0)$ for different $\operatorname{Pr}$

\begin{tabular}{lrlllr}
\hline \multicolumn{3}{c}{$\operatorname{Pr}=0.72$} & \multicolumn{5}{c}{$\operatorname{Pr}=10$} \\
\hline$n$ & $F_{n}^{\prime \prime}(0)$ & $\theta_{n}^{\prime}(0)$ & $n$ & $F_{n}^{\prime \prime}(0)$ & \multicolumn{1}{l}{$\theta_{n}^{\prime}(0)$} \\
\hline 0 & 0.676000 & -0.504600 & 0 & 0.419200 & -1.169400 \\
1 & 0.059500 & -0.231658 & 1 & 0.020150 & -0.231192 \\
2 & -0.003843 & 0.030660 & 2 & -0.002764 & 0.021149 \\
3 & 0.001008 & -0.030357 & 3 & 0.004576 & -0.014759 \\
4 & 0.010500 & 0.081054 & 4 & -0.008929 & 0.029316 \\
& $\operatorname{Pr}=1$ & & & $\operatorname{Pr}=100$ & \\
\hline$n$ & $F_{n}^{\prime \prime}(0)$ & $\theta_{n}^{\prime}(0)$ & $n$ & $F_{n}^{\prime \prime}(0)$ & $\theta_{n}^{\prime}(0)$ \\
\hline 0 & 0.642100 & -0.567100 & 0 & 0.251700 & -2.191000 \\
1 & 0.054220 & -0.232920 & 1 & 0.005751 & -0.223947 \\
2 & -0.003105 & 0.027835 & 2 & 0.000099 & 0.005879 \\
3 & 0.004505 & -0.021908 & 3 & 0.000726 & -0.004863 \\
4 & -0.000139 & 0.056546 & 4 & -0.002821 & 0.022791 \\
\hline
\end{tabular}

\subsection{Wall Shear Series}

First, we consider the wall shear which is proportional to $F^{\prime \prime}(0)$. For $\operatorname{Pr}=0.72$, the series for $F^{\prime \prime}(0)$ can be written from Table 1 as

$$
\begin{aligned}
F^{\prime \prime}(0)=0.67600 & +0.059500 \xi-0.003843 \xi^{2}+0.001008 \xi^{3} \\
& +0.010500 \xi^{4}
\end{aligned}
$$

As it stands, Eq. (30) is valid for small values of $\xi$ and cannot cover the range of $\xi$ from 0 to 10 as reported in [3]. However, the series can be remarkably improved if Shanks transformation is applied twice. Table 2 shows a sample calculation for $\xi=10$. The second column gives the partial sum $S_{n}$ while the result of the first application of Shanks transformation, denoted by $e\left(S_{n}\right)$, appears in the third column. The operator $e$ is defined as

$e\left(S_{n}\right)=\frac{S_{n+1} S_{n-1}-S_{n}^{2}}{S_{n+1}+S_{n-1}-2 S_{n}}$

The above transformation is next applied to the values appearing in the third column and the final result appears in the last column. The value of 1.0765 obtained here is under 4 per cent compared to the value of 1.117 by local nonsimilarity [3]. At lower values of $\xi$, the agreement between the present results and local nonsimilarity is still better. It is interesting to note from Table 2 how the wildly

Table 2. Application of Shanks transformation to series (30): $\xi=10$

\begin{tabular}{lrll}
\hline$n$ & \multicolumn{1}{c}{$S_{n}$} & $e$ & $e^{2}$ \\
\hline 0 & 0.6760 & & \\
1 & 1.2710 & 1.0375 & \\
2 & 0.8867 & 1.1649 & 1.0765 \\
3 & 1.8947 & 0.8769 & \\
4 & 106.8947 & & \\
\hline
\end{tabular}


fluctuating partial sums of the second column are smoothed out with the repeated application of Shanks transformation. We also note that the values of $F^{\prime \prime}(0)$ with just two and three terms of the series are 1.2710 and 0.8867 respectively which are obviously significantly in error compared to the value of 1.117 .

\section{Local Nusselt Number Series}

Following the usual convention, we express the heat transfer rate in terms of the ratio of local Nusselt number for the cylinder, $\left(\mathrm{Nu}_{x}\right)_{\mathrm{cyl}}$ and the local Nusselt number for a flat plate, $\left(\mathrm{Nu}_{x}\right)_{\mathrm{fp}}$. The series can be derived as

$$
\begin{aligned}
\frac{\left(\mathrm{Nu}_{x}\right)_{\mathrm{cyl}}}{\left(\mathrm{Nu}_{x}\right)_{\mathrm{fp}}}=1 & =\frac{\theta_{1}^{\prime}(0)}{\theta_{0}^{\prime}(0)} \xi+\frac{\theta_{2}^{\prime}(0)}{\theta_{0}^{\prime}(0)} \xi^{2}+\frac{\theta_{3}^{\prime}(0)}{\theta_{0}^{\prime}(0)} \xi^{3} \\
& +\frac{\theta_{4}^{\prime}(0)}{\theta_{0}^{\prime}(0)} \xi^{4}
\end{aligned}
$$

Using the information from Table 1 in Eq. (32) and applying the Shanks transformation gives the final results of Table 3. These results cover $\operatorname{Pr}=0.72,1,10$ and 100 , with each set covering a range of values of $\xi$. For comparison, the corresponding finite difference results of Cebeci [4] are also included. The values of $\xi$ were chosen so as to correspond exactly to the values used in [4] to facilitate comparison. The local nonsimilarity results of Minkowycz and Sparrow [3] for $\operatorname{Pr}=0.733$ are also included under the results for $\operatorname{Pr}=0.72$ to provide com-

\begin{tabular}{|c|c|c|c|c|c|}
\hline \multirow[b]{2}{*}{$\xi$} & \multicolumn{3}{|c|}{$\operatorname{Pr}=0.72$} & \multicolumn{2}{|l|}{$\operatorname{Pr}=1$} \\
\hline & Present & $\begin{array}{l}\text { Cebeci } \\
{[4]}\end{array}$ & $\begin{array}{l}\text { Minkowycz } \\
\text { \& Sparrow } \\
{[3]}\end{array}$ & Present & $\begin{array}{l}\text { Cebeci } \\
{[4]}\end{array}$ \\
\hline 0 & 1.000 & 1.000 & 1.000 & 1.000 & 1.000 \\
\hline 0.503 & 1.219 & 1.210 & 1.212 & 1.197 & 1.188 \\
\hline 1.064 & 1.445 & 1.422 & 1.428 & 1.399 & 1.380 \\
\hline 2.093 & 1.821 & 1.778 & 1.787 & 1.736 & 1.704 \\
\hline 3.364 & 2.232 & 2.177 & 2.170 & 2.106 & 2.068 \\
\hline 4.000 & 2.419 & 2.366 & 2.363 & 2.274 & 2.240 \\
\hline 5.030 & 2.700 & 2.660 & 2.674 & 2.527 & 2.508 \\
\hline 7.5 & 3.279 & - & 3.337 & & \\
\hline \multirow[t]{2}{*}{10} & 3.759 & - & 3.969 & & \\
\hline & \multicolumn{3}{|l|}{$\operatorname{Pr}=10$} & \multicolumn{2}{|l|}{$\operatorname{Pr}=100$} \\
\hline$\xi$ & Present & & $\begin{array}{l}\text { Cebeci } \\
{[4]}\end{array}$ & Present & $\begin{array}{l}\text { Cebeci } \\
{[4]}\end{array}$ \\
\hline 0 & 1.000 & & 1.000 & 1.000 & 1.000 \\
\hline 0.503 & 1.096 & & 1.096 & 1.051 & 1.051 \\
\hline 1.064 & 1.196 & & 1.196 & 1.107 & 1.107 \\
\hline 2.093 & 1.367 & & 1.373 & 1.207 & 1.204 \\
\hline 3.364 & 1.560 & & 1.575 & 1.327 & 1.318 \\
\hline 4.000 & 1.650 & & 1.672 & 1.385 & 1.373 \\
\hline 5.030 & 1.788 & & 1.823 & 1.478 & 1.460 \\
\hline
\end{tabular}

Table 3. Ratio of local Nusselt numbers, $\left(\mathrm{Nu}_{x}\right)_{\mathrm{xyl}} /\left(\mathrm{Nu}_{x}\right)_{\mathrm{fp}}$

\begin{tabular}{|c|c|c|c|c|}
\hline \multirow[b]{2}{*}{$\xi$} & \multicolumn{2}{|c|}{$\operatorname{Pr}=0.72$} & \multicolumn{2}{|l|}{$\operatorname{Pr}=1$} \\
\hline & Present & Cebeci [4] & Present & Cebeci [4] \\
\hline 0 & 1.000 & 1.000 & 1.000 & 1.000 \\
\hline 0.503 & 1.166 & 1.153 & 1.149 & 1.138 \\
\hline 1.064 & 1.338 & 1.312 & 1.304 & 1.281 \\
\hline 2.093 & 1.631 & 1.590 & 1.566 & 1.533 \\
\hline 3.364 & 1.957 & 1.911 & 1.859 & 1.825 \\
\hline 4.000 & 2.108 & 2.063 & 1.995 & 1.961 \\
\hline \multirow[t]{2}{*}{5.030} & 2.338 & 2.295 & 2.202 & 2.175 \\
\hline & \multicolumn{2}{|l|}{$\operatorname{Pr}=10$} & \multicolumn{2}{|l|}{$\operatorname{Pr}=100$} \\
\hline$\xi$ & Present & Cebeci [4] & Present & Cebeci [4] \\
\hline 0 & 1.000 & 1.000 & 1.000 & 1.000 \\
\hline 0.503 & 1.072 & 1.071 & 1.039 & 1.038 \\
\hline 1.064 & 1.149 & 1.147 & 1.081 & 1.079 \\
\hline 2.093 & 1.285 & 1.283 & 1.156 & 1.154 \\
\hline 3.364 & 1.400 & 1.441 & 1.246 & 1.242 \\
\hline 4.000 & 1.519 & 1.517 & 1.292 & 1.285 \\
\hline 5.030 & 1.638 & 1.636 & 1.366 & 1.352 \\
\hline
\end{tabular}

Table 4. Ratio of average Nusselt numbers, $\left(\mathrm{Nu}_{x}\right)_{\text {cyl }} /\left(\mathrm{Nu}_{x}\right)_{\mathrm{fp}}$

parison at higher values of $\xi$ namely 7.5 and 10 which are not covered in Cebeci's work. The results of local nonsimilarity as reported in [3] are restricted to $\operatorname{Pr}=0.733$ only and therefore the present results for other Pr cannot be compared for higher values of $\xi$. Upto $\xi=5$, the present results agree within about 2 per cent with the finite difference and local nonsimilarity and within 5 per cent upto $\xi=10$.

\subsection{Average Nusselt Number Series}

Finally, we consider the series for the ratio of average Nusselt numbers which follows as

$$
\begin{aligned}
\frac{\left(\overline{\mathrm{Nu}}_{x}\right)_{\mathrm{cyl}}}{\left(\overline{\mathrm{Nu}}_{x}\right)_{\mathrm{fp}}}=1 & +\frac{3}{4} \frac{\theta_{1}^{\prime}(0)}{\theta_{0}^{\prime}(0)} \xi+\frac{3}{5} \frac{\theta_{2}^{\prime}(0)}{\theta_{0}^{\prime}(0)} \xi^{2} \\
& +\frac{1}{2} \frac{\theta_{3}^{\prime}(0)}{\theta_{0}^{\prime}(0)} \xi^{3}+\frac{3}{7} \frac{\theta_{4}^{\prime}(0)}{\theta_{4}^{\prime}(0)} \xi^{4}
\end{aligned}
$$

Giving Eq. (33) the same treatment as Eq. (32), the final results are obtained as shown in Table 4. Once again Cebeci's results are quoted for comparison. The two results agree to within about 2 per cent in the range $\xi=0$ to 5. This degree of accuracy also holds beyond $\xi=5$. For example, the graphical result of [3] can be read to give the ratio $\left(\overline{\mathrm{Nu}}_{x}\right)_{\mathrm{cyl}} /\left(\mathrm{Nu}_{x}\right)_{\mathrm{fp}}=3.3$ at $\xi=10$ while the present result is 3.2453 . If one uses still higher value of $\xi$, say 20 , the twice Shank transformed result gives the ratio of 4.4012 which falls pretty close to local nonsimilarity solution if the curve in [3] is extrapolated to $\xi=20$. It would thus seem that present approach can be safely used upto $\xi=20$ and possibly even beyond that. 


\section{Final Remarks}

The use of Shanks transformation is one of a group of techniques that are available to improve the extended perturbation series. However, it is the simplest and can usually be trusted if the results show good degree of internal consistency as in the present problem. Other techniques such as Euler transformation, extraction of singularity, series reversion are also worthwhile as demonstrated in [10]. The present work has served to establish the usefulness of the extended series method in solving the nonsimilar boundary layer flows and it is hoped that the approach would find other applications.

\section{References}

1. LeFevre, E. J.; Ede, A. J.: Laminar Free Convection From the Outer Surface of a Vertical Circular Cylinder. Proc. Cong. Appl. Mech. 4 (1956) 175-183

2. Hama, F. R.; Recesso, J. V.; Christiaens, J.: The Axisymmetric Free Convection Temperature Field Along a Vertical Thin Cylinder. J. Aerospace Sci. 26 (1959) 335-342

3. Minkowycz, W. J.; Sparrow, E. M.: Local Nonsimilar Solutions for Natural Convection on a Vertical Cylinder. J. Heat Transfer. 96 (1974) 178-183

4. Cebeci, T.: Laminar Free Convective Heat Transfer From the Outer Surface of a Vertical Slender Circular Cylinder. Proc. Int. Heat Transfer. Conf. NC 1.4 (1974) 15-19
5. Sparrow, E. M.; Gregg, J. L.: Laminar Free Convection Heat Transfer From the Outer Surface of a Vertical Circular Cylinder. Trans. ASME 78 (1956) 1823-1829

6. Kuiken, H. K.: Axisymmetric Free Convection Boundary Layer Flow Past Slender Bodies. Int. J. Heat Mass Transfer. 11 (1968) $1141-1153$

7. Fujii, T.; Uehara, H.: Laminar Natural Convective Heat Transfer From the Outer Surface of a Vertical Cylinder. Int. J. Heat Mass Transfer. 13 (1970) 607-615

8. Minkowycz, W. J.; Sparrow, E. M.: Numerical Solution Scheme for Local Nonsimilarity Boundary Layer Analysis. Num. Heat Transfer. 1 (1978) 69-85

9. Van Dyke, M.: Extension, Analysis, and Improvement of Perturbation Series, Tenth Symposium, Naval Hydrodynamics. Cooper, R. D.; Doroff, S. W. (eds.): US Govt. Printing Office, Washington 1976

10. Aziz, A.: Analysis of Heat Transfer Problems with Computer Extended Perturbation Series. Num. Heat Transfer. 4 (1981) $123-130$

11. $\mathrm{Na}, \mathrm{T} . \mathrm{Y} .:$ Computational Methods in Engineering Boundary Value Problems. New York: Academic Press 1979

Prof. Dr. A. Aziz

Department of Mechanical Engineering

College of Engineering

P. O. Box 800

Riyadh, Saudi Arabia

Prof. Dr. T. Y. Na

Department of Mechanical Engineering

University of Michigan-Dearborn

Dearborn, Michigan, USA

Received February 16, 1981 